\title{
A sociedade de risco e a confiança nas relações de consumo
}

\author{
The society of risk and consumption relations trust
}

\begin{abstract}
Andreza Cristina Baggio
Doutoranda em Direito Econômico e Socioambiental, na linha da Pesquisa Direito e Sociedade, na Pontifícia Universidade Católica do Paraná (PUCPR), e membro do Grupo de Pesquisa de Direito Econômico e do Consumo, Curitiba, PR - Brasil, e-mail: andrezabaggio@hotmail.com
\end{abstract}

\section{Resumo}

Nossa atual sociedade pode ser caracterizada como uma sociedade de risco, resultante dos avanços da era industrial, da modernização da informação e da complexibilização dos processos de tomada de decisões. Analisar riscos significa problematizar o futuro, razão pela qual se faz necessária a consideração de suas consequências sociais. $O$ que se propõe neste trabalho é analisar o risco, sob o ponto de vista das relações de consumo. Desde o século XX, a sociedade está organizada a partir do fenômeno mundial das relações de consumo, massificada pelo crescente aumento de oferta de produtos e serviços, sendo o risco incorporado ao próprio modo de ser da sociedade pós-moderna e, pois, intimamente relacionado ao desenvolvimento da ciência, da tecnologia, e à tomada de decisões no processo de escolha por este ou aquele bem de consumo. Somem-se a esses riscos na relação de consumo os chamados riscos de desenvolvimento e a formação das redes de fornecedores, que buscam diminuir os riscos de suas atividades, transferindo-os 
aos consumidores. Tais situações deixam latente a vulnerabilidade do consumidor e reforçam a necessidade de tutela das legítimas expectativas deste nas relações de consumo. Essa tutela se faz por meio da proteção à lealdade, à boa-fé e, principalmente, à confiança depositada pelo consumidor na relação com o fornecedor. A confiança, portanto, deve ser vista pelo fornecedor como elemento valorativo dentro da estrutura empresarial, ganhando força de verdadeiro instrumento preventivo da proteção ao consumidor na sociedade de risco.

Palavras-chave: Sociedade de risco. Confiança. Vulnerabilidade e consumidor.

\section{Abstract}

Our present society can be characterized as the society at risk, due to the advances of the industrial age, the modernization of the information and decision-making processes. Analyze risks problematize means the future, why is it necessary to account for their social consequences. What is proposed in this paper is to analyze the risk from the point of view of relations of consumption. Since the twentieth century, society is organized from the worldwide phenomenon of relations of mass consumption, increasing the supply of products and services, and the risk embedded in the very way of being post-modern society, and therefore is closely related to the development of science, technology, and the decisionmaking process to choose this or that well for consumption. Add to these risks in relation to consumption, the so-called risk of development, and the formation of networks of suppliers, seeking to decrease the risks of their activities, transferring them to consumers. Such situations leave the latent vulnerability of the consumer, and reinforce the need for protection of legitimate expectations of those in the relations of consumption. This protection is by means of protecting the fairness, good faith and, above all, the trust paid by consumers in connection with the supplier. The trust, therefore, should be seen by the supplier as part valorization within the corporate structure, gaining real strength of preventive instrument of protection to consumers in society at risk.

Keywords: Society at risk. Trust. Vulnerability and consumer. 


\section{Introdução}

O presente trabalho tem por objetivo, inicialmente, reconhecer que o atual estágio da humanidade é o período que pode ser chamado de sociedade de risco, a qual resulta dos avanços da era industrial, da modernização da informação e da complexibilização dos processos de tomada de decisões.

Com o termo risco determina-se a problematização do futuro, e, portanto, o risco não pode ser analisado sem que se tomem em consideração os aspectos objetivos e suas consequências sociais. O que se propõe neste trabalho é analisar o risco, sob o ponto de vista das relações de consumo.

Desde o século XX, a sociedade está organizada a partir do fenômeno mundial das relações de consumo, massificada pelo crescente aumento de oferta de produtos e serviços, pelo império e crescimento do marketing e pela propagação do crédito fácil como elemento propulsor do desenvolvimento econômico.

O mundo vive em plena economia de consumo, razão pela qual é extremamente importante analisar o consumidor como parte mais fraca da relação jurídico-econômica e, principalmente, como importante mecanismo de engrenagem na sociedade de risco.

Em um segundo momento, busca este breve estudo analisar a vulnerabilidade do consumidor nessa sociedade de risco e a importância da tutela das suas legítimas expectativas, bem como da confiança que tais expectativas geram nessa parte vulnerável, motivo pelo qual se propõe uma breve análise do princípio da confiança nas relações de consumo.

Para tanto, faz-se uma breve síntese sobre o conceito de vulnerabilidade existente no Código de Defesa do Consumidor e uma exposição teórica sobre a confiança e sua significância como parâmetro balizador das relações entre fornecedores e consumidores, na busca de relações de consumo solidárias e justas. 


\section{Sociedade de risco e relações de consumo}

Para inicialmente problematizar a questão do risco na sociedade de consumo, valemo-nos aqui de Beck (1998), que apresenta cinco teses, por meio das quais pretende reafirmar que a sociedade que hoje vivemos trata-se de uma sociedade de risco. $\mathrm{O}$ citado autor expõe que o risco:

a) é aberto para processos sociais de sua definição;

b) relativiza a posição de classe, ou seja, atinge pobres e ricos, empresários ou assalariados, na poluição do ar, no envenenamento dos bens alimentícios por resíduos químicos, uma vez que os riscos da modernidade produzem efeitos bumerangue, recaindo também sobre os grupos sociais até então protegidos contra os males da industrialização;

c) não contradiz a lógica da valoração do capital, muito pelo contrário, a sociedade industrial produz o aproveitamento econômico dos riscos;

d) ressalta o papel da consciência e exige da sociologia contribuição para uma teoria do surgimento e divulgação da consciência do risco;

e) caracteriza a sociedade como catastrófica, em que o estado de emergência ameaça tornar-se o estado normal.

O mesmo autor prossegue, afirmando que, ao estudar o fenômeno do risco na sociedade pós-moderna, ${ }^{1}$ é possível observar que este

1 Luiz Fernando Coelho, em sua obra Saudade do futuro (2001), defende que a atual sociedade já vive na era da transmodernidade, assim conceituando-a: "Transmodernidade é um termo novo com o qual se faz referência à época atual; é igualmente uma nova categoria apta a catalisar a crítica à pós-modernidade utilizada inicialmente por Warat para enfatizar o caráter de transição da pós-modernidade, isto é, de passagem para novo ciclo histórico cujos contornos ainda não são bem nítidos, mas que tende a afirmar-se como tendo sua identidade própria. Esse autor assinala que a transição para o novo ciclo ocorre paralelamente ao acaso dos sentidos de modernidade; essa perda de sentidos faz-nos sentir-nos capturados pelo vazio, sendo a transmodernidade justamente esse sentido de vazio, algo à espera de outros sentidos organizadores no mundo" (BECK, 1998, p. 41). 
pode ser distinguido em três fases diversas. A primeira é que corresponde ao aparecimento da idade moderna, e da sociedade industrial, e na qual os riscos ainda eram incipientes e controláveis. É a chamada sociedade de riscos residuais.

Uma segunda fase destacada por Beck (1998, nota 3, p. 199) seria aquela do período compreendido entre o fim do século XIX e a primeira metade do século XX, em que o risco deixa de ser visto como um golpe de azar, passando a ser analisado de forma objetiva, inclusive sendo absorvido pelo Direito em termos de responsabilidade objetiva.

O terceiro momento ao qual se refere o autor é o que vivemos, aquele da era do estado social de direito, da expansão da informação, do desenvolvimento desmedido (BECK, 1998, p. 199).

Para Beck (1998), o momento atual representa a chamada era da modernidade reflexiva, a qual é, por definição, uma sociedade de risco. Assim, o autor sistematiza os riscos como as formas de lidar com os perigos e as inseguranças induzidas e introduzidas pelo processo de modernização.

Segundo ele, temos hoje uma sociedade de riscos fabricados, que extrapolam as realidades individuais e até mesmo as fronteiras temporais e territoriais - pois, se produzidos em uma região, continuamente afetam outras regiões, em grande escala. Esse processo é, sem dúvidas, um dos exemplos da globalização e, por que não dizer, do crescimento do comércio eletrônico em âmbito internacional, do uso indiscriminado da internet como meio de comunicação.

Não se pode negar, ainda, que dentre as principais características da atual sociedade de risco estão a globalização, o fim das barreiras entre as nações e, principalmente, o desenvolvimento da comunicação eletrônica e, como já dito, do comércio eletrônico.

Porém, a maior característica da atual sociedade de risco seria justamente a sua reflexividade, a qual Giddens (2002, p. 20) define como "a suscetibilidade da maior parte dos aspectos da atividade social, à revisão crônica à luz de novas informações ou conhecimentos”.

Feitas referidas considerações, importante lembrar que a característica marcante da nossa sociedade, a existência do risco, seja ele resultante 
da globalização, do processo de tomada de decisões ou da industrialização, está viva em nosso cotidiano, em nossos afazeres, enfim, em nossas relações de sobrevivência de convivência. É a pós-modernidade em nossas vidas.

A sociedade pós-moderna vive a lógica do tempo urgente e do risco. O tempo é urgente, a sociedade fragmentada, diferenciada, e isso implementa a complexidade do sistema social.

Sua proporção nada mais é do que a proporção da precaução, a qual é vista como um princípio internacional da pós-modernidade, como seu novo paradigma na busca de obter-se o risco zero, o qual, para Luhmann, assim como para Beck, jamais pode ser alcançado.

Luhmann (1983, p. 90) explica que, da perspectiva dos sistemas sociais, o risco deve ser tratado como um fenômeno da contingência advinda da complexidade da sociedade contemporânea. Ele pode ser caracterizado como unidade de distinção entre o que foi decidido e o que não foi decidido, ou o que poderia ter sido decidido. O risco é uma unidade de distinção que possibilita a diversos observadores percepções diferenciadas a respeito do mesmo objeto observado. É o que explica Francisco Carlos Duarte (2004).

E com essa sociedade de risco mistura-se a sociedade de consumo, já que com a produção de bens de consumo em massa surgem riscos incalculáveis e incontroláveis. É o que explica Fabiana Maria Martins Gomes de Castro (2002, p. 122-140).

De Castro (2002, p. 122-140) busca elucidar os motivos que causaram esse fenômeno social, expondo que a satisfação de múltiplas necessidades levou à produção em massa de produtos de consumo, por meio de processos perigosos, sendo que, na maioria das vezes, não é possível conhecer de início os efeitos de citados produtos.

Para esta autora, a sociedade de consumo acaba por tornar o sujeito um objeto manipulável, sendo que nas relações massificadas é difícil manter-se o equilíbrio contratual e a proteção da dignidade do contratante vulnerável. O risco, então, é incorporado ao próprio modo de ser da sociedade pós-moderna, pois está intimamente relacionado ao desenvolvimento da ciência, da tecnologia, e à tomada de decisões no processo de escolha por este ou aquele bem de consumo. 
Consumir é um ato que envolve riscos, pois está baseado na tomada de decisão pelo consumidor, a qual, no caso dos produtos e serviços postos no mercado de massa, é fortemente influenciada e influenciável. Isso porque grande parte das relações de consumo atualmente é resultado dos efeitos da publicidade sobre os seus respectivos alvos - os consumidores. Milhares de pessoas acabam contratando a compra de bens e a prestação de serviços, tomando em consideração os anúncios veiculados nos meios de comunicação.

É a publicidade criando necessidades e expondo o consumidor ao risco de sua decisão, razão pela qual a responsabilidade resultante desta há de ser sempre maximizada, em detrimento do fornecedor que deixe de respeitar a transparência e a boa-fé. Como bem lembra Bittar (1981),

a publicidade responde, em seu íntimo, a uma necessidade do homem: a de comunicar-se, tornando-se, de outro lado, centro transmissor de idéias. Com efeito, a mensagem através da qual o bem é apresentado ao público vaza-se, não raro, em termos didáticos, acompanhada, pois, de ensinamentos a respeito da matéria.

Ademais, o consumidor encontra-se na sociedade massificada exposto ao que se pode chamar de risco do desenvolvimento, aquele que não pode ser cientificamente conhecido no momento do lançamento do produto no mercado - e que somente o será após um período de uso do produto, mostrando-se então perigoso à vida, saúde ou segurança do consumidor, em virtude do conhecimento posterior a respeito dos efeitos colaterais ou prejudiciais. Exemplo clássico é o do caso dos medicamentos (DE CASTRO, 2002, p. 132) e, recentemente, a questão dos alimentos transgênicos. ${ }^{2}$

Tal espécie de risco é consequência natural do avanço tecnológico, e inclusive possibilitou ao ser humano a utilização de substâncias

2 Notícia publicada em 15 de junho de 2008 no jornal $A$ Tarde dá conta de que os consumidores não estão informados sobre a legislação existente sobre transgênicos no Brasil, bem como sobre quais produtos que consomem para sua alimentação possuem esse tipo de elemento em sua composição, ou mesmo quais os efeitos desses elementos em relação à saúde. Disponível em: <www.atarde.com. br/economia/notícia.jsf?id=902403>. Acesso em: 15 jun. 2008. 
químicas das mais variadas na elaboração de medicamentos e produtos alimentícios. Porém, em muitas destas situações é impossível saber de antemão os efeitos deste produto, antes de colocá-lo no mercado. Como bem afirma Cavalieri Filho (1998, p. 35),

o desenvolvimento tecnológico e científico, a par dos indiscutíveis benefícios que trouxe para todos nós, aumentou enormemente os riscos do consumidor concepção, um único erro de produção pode causar danos a milhares de consumidores, uma vez que os produtos são fabricados em série, em massa, em grande quantidade.

Mas não é só a tais espécies de riscos que o consumidor está exposto nas relações a que se submete. Há que se considerar também os riscos da atividade empresarial, que muitas vezes acabam sendo transferidos indevidamente ao consumidor.

Fornecedores, ao colocarem seus produtos e serviços no mercado, não o fazem gratuitamente - buscam lucro, e em boa parte das situações transferem ao consumidor o risco do seu negócio, quando deixam de informar corretamente as especificidades daquilo que estão ofertando, quando não prestam corretamente o serviço ou quando o produto que colocam no mercado não atinge a expectativa do consumidor.

E mais: fenômeno muito comum em nossos dias é aquele em que vários empresários reúnem-se, cada um com sua especialidade, para satisfazer muitos consumidores, compartilhando entre si os efeitos positivos e negativos do negócio, os quais alcançam as prestações próprias e também as alheias, buscando assim diluir entre eles os riscos da atividade empresária.

Como esclarece Iturraspe (1999, p. 9), ${ }^{3}$ ao explicar este fato notório na sociedade de risco,

3 "El individualismo contractual viene dejando paso a la contractación grupal. Y ello no resulta caprichoso, puesto que lo perseguido es ahora un resultado negocial, una operación económica global, buscada a través de un programa que una o varias empresas se proponen. Se trata ahora de contratos entrelazados en un conjunto económico, persiguiendo lo que se ha dado em llamar una misma prestación esencial, un todo contractual para un mismo y único negocio. El acento aparece puesto en el negocio y no en el contrato" (ITURRASPE, 1999, p. 9). 
o individualismo contratual vem deixando espaço à contratação grupal. E isto não é casual, pois o que se persegue é agora um resultado negocial, uma operação econômica global, procurada através de um programa, que uma ou várias empresas se propõem. Trata-se, agora, de contratos entrelaçados num conjunto econômico, perseguindo o que passou a se chamar uma mesma prestação essencial, um todo contratual, para um mesmo e único negócio. O realce é dado ao negócio, e não ao contrato.

Torna-se então comum o fenômeno das redes contratuais entre fornecedores, o qual está intimamente relacionado com as contratações na sociedade de massas, em que grande parte das empresas, na busca de minimizar os riscos de seu negócio, acabam por firmar grandes redes de contratos para o fornecimento de bens e serviços. Nestas situações, a existência de um contrato somente se justifica porque existem também outros que funcionam como um sistema, não se justificando a existência de um negócio, sem a existência do outro.

Com a utilização de cadeias de contratos, as empresas acabam por abranger uma massa maior de consumidores, já que não se encontram limitados a lhes oferecer um bem, produto ou serviço.

Exemplo bastante claro da conexidade entre contratos é a contratação por meio de cartões de crédito, pois em uma visão sistêmica existe um nexo de acessoriedade nos contratos entre emissor e fornecedor (cadeia de fornecimento), entre consumidor e operadora de cartão (cadeia de consumo), e a relação principal de consumo, que é o contrato entre o consumidor e o fornecedor. ${ }^{4}$

4 Para compreender a questão relativa ao cartão de crédito, é obra de fundamental importância a de Gerson Luiz Carlos Branco (1998). Em seu livro, o autor explica amplamente a noção de sistema jurídico na teoria contratual, e salienta que: "a adequação da noção de sistema ao cartão de crédito dá-se pela existência de um conjunto de contratos que integram os atos de autonomia privada ao ordenamento jurídico nacional e pela presença de laços que garantem a conexão dos diversos contratos que formam a operação econômica do cartão de crédito, cuja unidade é mais do que meramente normativa, mas também funcional, em face da comunidade de finalidades específicas entre os contratos". 
Segundo Teyssie (1975, p. 8-10), é possível afirmar que as redes contratuais surgem como resultado da complexidade dos processos de produção e das relações comerciais em geral, da crescente especialização das atividades, acompanhadas da divisão de trabalho, da circulação cada vez mais rápida das riquezas e bens, da ampliação do setor geográfico de atuação das empresas, dentre outros fatores.

Como já observamos, as redes contratuais têm por finalidade facilitar ou realizar o consumo, e o jurista, portanto, deve estar atento ao fenômeno da interligação contratual em redes, pois de uma visão real e socialmente útil da multiplicidade e complexidade das relações contratuais pós-modernas, é possível que acabe resultando uma visão formalista e reduzida a impedir a realização da função social do contrato (TORRES, 2007, p. 65).

Pela mesma razão, é preciso impedir que esta formação de verdadeiras cadeias de fornecedores prejudique a função do contrato de consumo, que é o acesso aos bens necessários à inserção do ser em sociedade, e sua digna sobrevivência, como o acesso à saúde, moradia, alimentação, educação e vestuário.

Por todo o exposto, dizer simplesmente que o comércio massificado e globalizado de nossa sociedade pós-moderna acirra a concorrência é deixar de observar todos os meandros do processo produtivo. É preciso lembrar que existem duas formas de se reduzir custos: o uso de tecnologias avançadas ou então o desrespeito aos padrões de trabalho e de produção. É o que explica Ulrich Beck (1999, p. 207).

É justamente em virtude desta constatação, que se faz necessária no atual estágio da produção industrial uma tutela efetiva aos afetados pela massificação da produção, ou seja, aqueles que se encontram no fim da cadeia produtiva, no caso, os consumidores, os quais, expostos às práticas de redução de custos na industrialização dos bens de consumo, e de sua publicidade no mercado, acabam sujeitos aos riscos do processo, que devem ser arcados tão somente pelos fornecedores. 


\section{Vulnerabilidade e confiança nas relações de consumo}

É certo dizer que em nossa sociedade pós-industrial observamse modificações de grande profundidade, tanto no tratamento da produção, quanto no tratamento do comportamento do homem, no momento da escolha do que vai consumir.

A produção em massa passou a oferecer quantidades cada vez maiores de produtos, enquanto que as técnicas de marketing e propaganda influem nos processos de escolha de modo tão incisivo que na maioria das situações a escolha é fabricada pela criação artificial de necessidades.

Diante deste cenário, é importante reconhecer que o consumidor é notadamente a parte vulnerável na relação de consumo. Esta vulnerabilidade foi expressamente reconhecida pelo Código de Defesa do Consumidor Brasileiro, em seu artigo $4^{\circ}$, inciso I. ${ }^{5}$

A principal preocupação da Lei 8.078/90, o Código de Defesa do Consumidor (CDC), é assegurar o equilíbrio das obrigações contratuais e das relações que possam ser consideradas de consumo, por meio de uma regulamentação específica, que busca antes de tudo a manutenção da boa-fé, não importando o meio físico em que se formem.

Em seu artigo $2^{\circ}$, o CDC dispõe: "Consumidor é toda pessoa física ou jurídica que adquire ou utiliza produtos ou serviços como destinatário final".

Sem apresentar aqui toda a discussão doutrinária a respeito do conceito de destinatário final, e apenas lembrando da existência de uma

5 Art. 4o - A Política Nacional das Relações de Consumo tem por objetivo o atendimento das necessidades dos consumidores, o respeito à sua dignidade, saúde e segurança, a proteção de seus interesses econômicos, a melhoria da sua qualidade de vida, bem como a transparência e harmonia das relações de consumo, atendidos os seguintes princípios:

I- reconhecimento da vulnerabilidade do consumidor no mercado de consumo; [...]. 
corrente maximalista, ${ }^{6}$ e outra finalista, ${ }^{7}$ inevitável é a conclusão de que este conceito deverá ser interpretado de forma sistemática, tomando em consideração a finalidade do próprio Código de Defesa do Consumidor.

Assim, sempre que exista um consumidor como parte vulnerável na relação, uma parte para a qual não se tornou possível impor as suas condições contratuais, ou mesmo questionar dados técnicos do contrato, há que se aplicar as regras específicas da legislação consumerista.

O conceito de consumidor no Código de Defesa do Consumidor pode exceder os contornos expostos no artigo $2^{\circ}$. Este diploma legal equipara a consumidor todas as pessoas que venham a intervir na relação de consumo, nos termos do parágrafo único do artigo $2^{\circ}$, bem como as vítimas dos acidentes de consumo, de acordo com o artigo 17, e, por fim, todas as pessoas que de alguma forma estejam expostas às práticas comerciais e contratuais, nos termos do artigo 29.

Dispõe o artigo 29 do CDC: "Para os fins deste capítulo e do seguinte, equiparam-se aos consumidores todas as pessoas determináveis ou não, expostas às práticas nele previstas".

Mencionado artigo está localizado no Diploma Consumerista exatamente no Capítulo V, remetendo-se sua aplicabilidade ao Capítulo VI, sendo que ambos os capítulos tratam, respectivamente, das práticas comerciais e da proteção contratual. E dentre as práticas comerciais encontra-se justamente a publicidade, na seção III do Capítulo V.

6 Filiam-se a essa corrente maximalista autores como Antônio Carlos Efing, Luiz Antônio Rizzato Nunes, dentre outros. Cabe esclarecer que a posição adotada neste trabalho é aquela referente à corrente maximalista, com o que há que se concordar com as palavras de Efing (2004, p. 44): "não resta dúvida de que nos filiamos à corrente maximalista, isto porque somos da opinião de que o CDC veio para introduzir nova linha de conduta entre os partícipes da relação jurídica de consumo. Assim, não importa ter vislumbrada a relação de hipossuficiência do consumidor, como querem alguns autores, mas sim, uma completa moralização das relações de consumo da sociedade brasileira, onde somente permanecerão nos diversos segmentos da cadeia de consumo aqueles (pessoas físicas ou jurídicas) que assumirem esta posição com todos os seus ônus e encargos, dentre os quais o atingimento da perfeição no fornecimento de produtos e serviços, em total consideração ao consumidor (adquirente ou utente deste produto ou serviço)".

7 Filiam-se à corrente finalista Cláudia Lima Marques, Alcides Tomasetti Jr., Eros Grau, dentre outros. 
Assim como afirma Coelho (1991, p. 148): "o legislador considera que a tutela, nestas áreas específicas, não se pode restringir ao momento posterior ao acordo entre o consumidor e o fornecedor, mas, ao contrário, deve antecedê-lo, para que tenha um caráter preventivo e mais amplo".

Como observa Benjamin (1992, p. 147), o artigo $2^{\circ}$ do CDC vê o consumidor concretamente, enquanto que no artigo 29 o consumidor é visto abstratamente. Visa a lei a evitar o dano in abstrato, por meio da proteção a todas as pessoas que se encontrem expostas a ele. Aliás, a aplicabilidade deste artigo almeja a proteção ampla à boa-fé, que atua como princípio geral no Código de Defesa do Consumidor, e à vulnerabilidade, como característica que identifica o consumidor.

O Código, portanto, baseia a proteção do consumidor, da parte vulnerável na relação contratual, na proteção à boa-fé, na necessidade de informação adequada, na transparência, para que aquele sujeito exposto às práticas da sociedade massificada não venha a arcar com os riscos do negócio, sem direito a qualquer espécie de indenização no caso de danos.

Mas não é só. O Código busca também, ao tutelar a vulnerabilidade do consumidor, reforçar a confiança deste na relação pactuada, e nos interesses legítimos que estão sendo colocados em destaque durante a contratação.

Nas relações negociais, é evidente que quando alguém realiza certo ato ou manifesta sua vontade no sentido de contratar, o faz confiando na sinceridade do outro contratante, nascendo aí legítimas expectativas, que devem ser tuteladas pelo Direito, sendo este o principal fundamento da tutela da confiança nas relações de consumo. ${ }^{8}$ Segundo Cordeiro (1987, p. 1234),

8 O Superior Tribunal de Justiça decidiu, em acórdão paradigma, cuja ementa ora se transcreve, a necessidade de tutela a confiança do consumidor, diante das legítimas expectativas geradas pelo contrato de consumo: "Direito do consumidor. Contrato de seguro de vida inserido em contrato de plano de saúde. Falecimento da segurada. Recebimento da quantia acordada. Operadora do plano de saúde. Legitimidade passiva para a causa. Princípio da boa-fé objetiva. Quebra de confiança. Denunciação da lide. Fundamentos inatacados. Direitos básicos do consumidor de acesso à Justiça e de facilitação da defesa de seus direitos. Valor da indenização a título de danos morais. Ausência 
a confiança exprime [...] a situação em que uma pessoa adere, em termos de atividade ou de crença, a certas representações, passadas, presentes ou futuras, que tenha por efetivas. O princípio da confiança explicitaria o reconhecimento dessa situação e a sua tutela.

O princípio da confiança é intrínseco às relações de consumo, pelos conexos princípios da lealdade e da boa-fé objetiva, tendo a característica de constituir normas de conduta, entre as quais as de informação e as de proteção aos legítimos interesses da parte vulnerável na cadeia de consumo (MARTINS-COSTA; BRANCO, 2002, p. 133). Na lição de Moraes (2005, p. 3-22):

em busca do equilíbrio contratual, a lei passa a favorecer determinados interesses sociais, valorizando a confiança depositada no vínculo, as expectativas legítimas que nasceram no outro contratante, o qual confiou na postura, nas obrigações assumidas e no vínculo criado através da declaração. Assim, a teoria da confiança atribui responsabilidade àquele que, por seu comportamento na sociedade, gera no outro contratante justificada expectativa no adimplemento de determinadas obrigações.

de exagero. Litigância de má-fé. Reexame de provas. Os princípios da boa-fé e da confiança protegem as expectativas do consumidor a respeito do contrato de consumo. A operadora de plano de saúde, não obstante figurar como estipulante no contrato de seguro de vida inserido no contrato de plano de saúde, responde pelo pagamento da quantia acordada para a hipótese de falecimento do segurado se criou, no segurado e nos beneficiários do seguro, a legítima expectativa de ela, operadora, ser responsável por esse pagamento. - A vedação de denunciação da lide subsiste perante a ausência de impugnação à fundamentação do acórdão recorrido e os direitos básicos do consumidor de acesso à Justiça e de facilitação da defesa de seus direitos. - Observados, na espécie, os fatos do processo e a finalidade pedagógica da indenização por danos morais (de maneira a impedir a reiteração de prática de ato socialmente reprovável), não se mostra elevado o valor fixado na origem. - $\mathrm{O}$ afastamento da aplicação da pena por litigância de má-fé necessitaria de revolvimento do conteúdo fático-probatório do processo. Recurso especial não conhecido" (REsp 590.336/SC, rel. ministra Nancy Andrighi, Terceira Turma, julgado em 07/12/2004, DJ 21/02/2005, p. 175. Grifo nosso). 
A proteção da confiança se realiza de duas formas principalmente: por meio de disposições legais específicas, e por meio de institutos gerais. As primeiras correspondem ao resultado do reconhecimento, pelo Direito, de situações típicas nas quais uma pessoa que legitimamente acredita em certo estado de coisas receba uma vantagem que, de outro modo, não lhe seria concedida.

Cabe aqui lembrar, ainda que brevemente, dos dispositivos legais referentes à proteção dos efeitos jurídicos decorrentes de situações em que se aplica a teoria da aparência. ${ }^{9}$ Observa-se aqui claramente a atuação da lei como limitadora da autonomia privada, com o intuito de proteger determinados interesses sociais, valorizando a confiança depositada no vínculo, as expectativas e a boa-fé das partes contratantes (MARQUES, 2005, p. 191).

A segurança das relações negociais está intimamente ligada à lealdade e à confiança das partes contratantes, cabendo às partes, sempre, "agir com cooperação e lealdade, a fim de proteger os interesses recíprocos e o êxito do vínculo" (MELLO, 2002, p. 153).

9 A Teoria da Aparência é amplamente aceita pela doutrina pátria, e tem por fundamento a efetiva proteção daquele que, de boa-fé, confia na veracidade do negócio que lhe é apresentado. Para ilustrar a questão, segue acórdão paradigma tratando da questão: ATO JURÍDICO - Ação de anulação Ato praticado, isoladamente, por Diretor-Presidente, resultando responsabilidade comercial para a sociedade - Conduta contrária ao designado nos estatutos - Prévio conhecimento da outra parte contratante sobre a exigência estatutária de que a representação fosse feita por dois diretores Nulidade do ato - Inaplicabilidade da Teoria da aparência - Recomendada apuração de eventual responsabilidade penal - Inteligência dos arts. 17 e 82, do CC - Procedência decretada. TACSP, $7 \underline{a}$ Câm. - Ap.-rev. 420.019-00/5 - rel. Luiz Henrique - j. 16/05/1995; v.u... Trata-se de acórdão em ação de anulação de negócio jurídico (aditivo de contrato de locação) praticado por preposto que não tinha, isoladamente, poderes para firmar o negócio em nome da sociedade locadora. $O$ instrumento originário havia sido firmado por dois prepostos de cada uma das sociedades contratantes, conforme exigido pelos estatutos. Já expirado o prazo daquele contrato, e havendo valores relativos a aluguéis vencidos pendentes, foi firmado aditivo contratual, em que, pela empresa-requerente, somente um preposto seu assinou. É de se ressaltar que neste aditivo foram incluídas diversas cláusulas prejudiciais à empresa locadora. Com base na Teoria da Aparência, a empresa locadora defendeu a validade do negócio jurídico, alegando que, ainda que não preenchidos os requisitos estatutários para validade do contrato firmado, deveriam ser validados os efeitos produzidos em razão da imagem de aparência de validade do negócio que justamente criou. 
Nas relações de consumo, é preciso que as partes ajam "com lealdade recíproca, dando as informações necessárias e evitando criar expectativas que sabem destinadas ao fracasso, impedindo a revelação de dados obtidos em confiança, não realizando rupturas abruptas e inesperadas das conservações, etc." (AZEVEDO, 1996, p. 25).

E mais: o princípio da igualdade preconizado na Constituição Federal de 1988 , em seu artigo $5^{\circ}$, caput, implica a harmonização e a adequação do sistema como um todo, e, considerando o ideal de justiça, busca promover entre as partes uma relação equilibrada e equitativa. Assim, sendo o contrato uma união de interesses equilibrada, enquanto instrumento de cooperação leal e probo, é salutar a proteção da confiança mútua. E no que tange às relações de consumo, a necessidade de tutela da confiança depositada pelo consumidor no vínculo firmado se traduz pelo reconhecimento expresso de sua vulnerabilidade.

Ademais, é preciso lembrar sempre que a confiança é elemento indispensável para a manutenção do grupo social, e não só das relações entre fornecedor e consumidor. Como explica Cordeiro (2005, p. 414),

na sua falta, qualquer sociedade se esboroa. Em termos interpessoais, a confiança instalada aloca os protagonistas à mercê uns dos outros: o sujeito confiante abranda as suas defesas, ficando vulnerável. Seguidamente, todos os investimentos, sejam eles econômicos ou meramente pessoais, postulam a credibilidade das situações: ninguém dá hoje para receber (apenas) amanhã, se não houver confiança nos intervenientes e nas situações. Por fim, a confiança e a sua tutela correspondem a aspirações éticas elementares. A pessoa defraudada na sua confiança é, desde logo, uma pessoa violentada na sua sensibilidade moral. Paralelamente, o agente que atinja a confiança alheia age contra um código ético imediato.

A tutela da confiança pelo Direito é realizada com base no princípio da boa-fé objetiva. O Código Civil de 2002, em seu artigo 422, ${ }^{10}$ traz de forma

${ }^{10}$ Art. 422. Os contratantes são obrigados a guardar, assim na conclusão do contrato, como em sua execução, os princípios de probidade e boa-fé. 
expressa o princípio da boa-fé objetiva, quando dispõe que os contratantes devem guardar a boa-fé e a probidade na conclusão do contrato e na sua execução, expressando este princípio como verdadeira cláusula geral de conduta. Para Luhmann (1983, p. 27), em uma sociedade hipercomplexa como a nossa, quando os mecanismos de interação pessoal ou institucional, para assegurar a confiança básica na atuação, não são mais suficientes, pode aparecer uma generalizada crise de confiança, na efetividade do próprio direito. Significa dizer que o Direito está legitimado exatamente na proteção das expectativas legítimas do ser humano e da confiança da vida em sociedade. Nas palavras de Marques (2005, p. 31):

hoje a confiança é um princípio diretriz das relações contratuais, merece proteção e é fonte autônoma de responsabilidade. Em outras palavras, as condutas na sociedade e no mercado de consumo, sejam atos, dados ou omissões, fazem nascer expectativas legítimas naqueles em que espertamos a confiança, os receptores de nossas informações ou dados, em resumo, confiar é acreditar, é manter, com fé, a fidelidade, a conduta, as escolhas e o meio; confiança é a aparência, informação, transparência, diligência e ética no exteriorizar vontades negociais.

A confiança é um elemento central da vida em sociedade e, em sentido amplo, é a base da atuação do indivíduo (MARQUES, 2006, p. 31) e nas relações de consumo, deve ter por foco os principais atores das relações jurídica, ou seja, os consumidores, os fornecedores e os vínculos que se foram através dos métodos de marketing.

Portanto, se no Código Civil o princípio da confiança está expressamente previsto no artigo 422, que trata da boa-fé objetiva, no Código de Defesa do Consumidor, além de expressamente previstos nos incisos I e II do artigo $4^{\circ}{ }^{11}$ que tratam da vulnerabilidade do consumidor e do prin-

${ }^{11}$ Art. 4ㅇ - A Política Nacional das Relações de Consumo tem por objetivo o atendimento das necessidades dos consumidores, o respeito à sua dignidade, saúde e segurança, a proteção de seus interesses econômicos, a melhoria da sua qualidade de vida, bem como a transparência e harmonia das relações de consumo, atendidos os seguintes princípios: 
cípio da boa-fé objetiva, o princípio da confiança permeia todo o sistema de proteção ao consumidor.

Isto porque é possível dizer que entre a confiança e o futuro existe uma relação de previsibilidade no comportamento empresarial, e quanto maior for a confiança que se desperte no consumidor, maior será o grau de certeza quanto ao comportamento dos atores na relação de consumo (WEINGARTEN, 2000, p. 35), e por esta razão a confiança deve ser privilegiada como verdadeiro instrumento preventivo de proteção aos interesses do consumidor na sociedade de risco.

É preciso, então, que os fornecedores tomem consciência, que a confiança tem o mesmo valor que qualquer outro capital físico dentro da empresa, posto que a expectativa da confiança nasce fundamentalmente a partir da credibilidade tornada objetiva, orienta o comportamento do consumidor e guia as suas decisões (WEINGARTEN, 2000, p. 39).

\section{Considerações finais}

Em tempos pós-modernos, da quebra de paradigmas e de mudanças na estrutura do Direito Privado, a crise da confiança da sociedade nos institutos jurídicos é algo que não pode deixar de ser analisado, principalmente se tomado em consideração do ponto de vista da análise dos riscos que envolvem as relações de consumo.

Nessa verdadeira sociedade de risco que hoje vivemos, em que o consumidor resta exposto às práticas de marketing e publicidade, ao risco de desenvolvimento de novas técnicas e, inclusive, de novas formas de produtos e gêneros alimentícios, como é o caso dos polêmicos alimentos

\footnotetext{
I- reconhecimento da vulnerabilidade do consumidor no mercado de consumo; [...]

III - harmonização dos interesses dos participantes das relações de consumo e compatibilização da proteção do consumidor com a necessidade de desenvolvimento econômico e tecnológico, de modo a viabilizar os princípios nos quais se funda a ordem econômica (art. 170, da Constituição Federal), sempre com base na boa-fé e equilíbrio nas relações entre consumidores e fornecedores; [...].
} 
transgênicos, é preciso que a vulnerabilidade do consumidor seja sempre respeitada.

Vulnerabilidade e confiança estão intimamente ligadas, de acordo com o sistema preventivo do Código de Defesa do Consumidor, que prevê punição para a inobservância ao direito de informação do consumidor, para as práticas pré-contratuais abusivas e, principalmente, para a violação à quebra da confiança, que ocorre quando as legítimas expectativas do consumidor deixam de ser atendidas pelo fornecedor.

Como já foi exposto, é preciso que exista a consciência do fornecedor de que a confiança na marca, no produto e no cumprimento pelo fornecedor da proposta apresentada reveste-se de verdadeiro elemento da atividade empresarial, que se soma ao próprio nome do fornecedor ou da rede de fornecedores.

É com esta mentalidade que as práticas empresariais tornar-se-ão mais solidárias, e será possível a realização da verdadeira função social da empresa: a formação de uma sociedade de risco, e de consumo, com justiça social e igualdade.

\section{Referências}

AZEVEDO, A. J. de. Responsabilidade pré-contratual no Código de Defesa do Consumidor: estudo comparativo com a responsabilidade pré-contratual no direito comum. Revista de Direito do Consumidor, n. 18, p. 23-31, abr./jun. 1996. BECK, U. La sociedad del riesgo. Buenos Aires: Paidós, 1998.

BECK, U. 0 que é globalização? Equívocos do globalismo: respostas à globalização. Tradução de André Carone. São Paulo: Paz e Terra, 1999.

BENJAMIN, A. H. Código brasileiro de defesa do consumidor comentado pelos autores do anteprojeto. Rio de Janeiro: Forense Universitária, 1992.

BITTAR, C. A. Direito de autor na obra publicitária. São Paulo: Revista dos Tribunais, 1981. 
BRANCO, G. L. C. $O$ sistema contratual do cartão de crédito. São Paulo: Saraiva, 1998.

CAVALIERI FILHO, S. Programa de responsabilidade civil. 2. ed. São Paulo: Malheiros, 1998.

COELHO, F. U. et al. Comentários ao código de proteção do consumidor. Coord. Juarez de Oliveira. São Paulo: Saraiva, 1991.

COELHO, L. F. Saudade do futuro. Florianópolis: Fundação Boiteux, 2001.

CORDEIRO, A. M. Da boa-fé no direito civil. Coimbra: Almedina, 1987. v. 1.

CORDEIRO, A. M. da R. e M. Tratado de direito civil português. 3. ed. Coimbra: Almedina, 2005. tomo 1.

DE CASTRO, F. M. M. G. Sociedade de risco e o futuro do consumidor. Revista de Direito do Consumidor, v. 11, n. 44, p. 123-136, 2002.

DUARTE, F. C. Direito fundamental à decisão urgente. In: DUARTE, F. C. Tutela de urgência e risco: em defesa dos direitos fundamentais. Curitiba: Juruá, 2004. p. 69-92.

EFING, A. C. Fundamentos do direito das relações de consumo. 2. ed. Curitiba: Juruá, 2004.

GIDDENS, A. Mundo em descontrole: o que a globalização está fazendo de nós. São Paulo: Record, 2002.

ITURRASPE, J. M. Contratos conexos: grupos y redes de contratos. Buenos Aires: Rubinzal Culzoni, 1999.

LUHMANN, N. Sociologia do direito II. Rio de Janeiro: Tempo Brasileiro, 1983.

MARQUES, C. L. Contratos no código de defesa do consumidor. 5. ed. São Paulo: Revista dos Tribunais, 2005.

MARQUES, C. L. A confiança no comércio eletrônico. São Paulo: Revista dos Tribunais, 2006. 


\section{MARTINS-COSTA, J.; BRANCO, G. Diretrizes teóricas do novo Código Civil} Brasileiro. São Paulo: Saraiva, 2002.

MELLO, A. M. T. de. A função social do contrato e o princípio da boa-fé, no Novo Código Civil brasileiro. Revista Síntese de Direito Civil e Processual, ano III, n. 16, p. 150-161, mar./abr. 2002.

MORAES, M. C. B. de. Notas sobre a promessa de doação. Revista Trimestral de Direito Civil, n. 24, p. 3-22, out./dez. 2005.

TEYSSIE, B. Les groupes de contracts. Paris: Libraire Generále de Droit et de Jurisprudence, 1975.

TORRES, A. C. B. Teoria contratual pós-moderna: as redes contratuais da sociedade de consumo. Curitiba: Juruá, 2007.

WEINGARTEN, C. El valor económico de la confianza para empresas y consumidores. Revista de Direito do Consumidor, n. 33, p. 33-50, jan./mar., 2000.

Recebido: 19/07/2009

Received: 07/19/2009

Aprovado: 25/08/2009

Approved: 08/25/2009 